\title{
Apple Blossoms from a Swiss Orchard with Low-Input Plant Protection Regime Reveal High Abundance of Potential Fire Blight Antagonists
}

\author{
Florian Gschwend, ${ }^{1}$ Andrea Braun-Kiewnick, ${ }^{2,3}$ Franco Widmer, ${ }^{1}$ and Cosima Pelludat ${ }^{2, \dagger}$ \\ ${ }^{1}$ Molecular Ecology, Agroscope, Reckenholzstr. 191, CH-8046 Zürich, Switzerland \\ ${ }^{2}$ Plant Pathology and Zoology in Fruit and Vegetable Production, Agroscope, Müller-Thurgau-Strasse 29, CH-8820 Waedenswil, Switzerland \\ ${ }^{3}$ Institute for Epidemiology and Pathogen Diagnostics, Julius Kühn-Institut Federal Research Centre for Cultivated Plants, Messeweg 11-12, \\ D-38104 Braunschweig, Germany
}

Accepted for publication 18 December 2020.

\begin{tabular}{|c|c|}
\hline \multicolumn{2}{|c|}{ ABSTRACT } \\
\hline $\begin{array}{l}\text { Erwinia amylovora causes fire blight, a serious disease of } \\
\text { Rosaceae plants, including apple and pear. A predominant } \\
\text { path of bacterial infection is entry through nectartodes after } \\
\text { multiplication on the stigma. Depending on the inhibitory abilities } \\
\text { of the native blossom microbiota, it may control the outbreak of } \\
\text { fire blight and, therefore, may bar potential plant protection with } \\
\text { reduced input of synthetic chemicals. Blossoms of five apple } \\
\text { varieties in a low-input orchard, which had no fire blight history } \\
\text { despite disease outbreaks in close proximity, were analyzed } \\
\text { to assess bacterial and fungal communities. Metabarcoding } \\
\text { indicated low microbial diversity and the presence of a few } \\
\text { dominant operational taxonomic units (OTUs), including known } \\
\text { fire blight antagonists such as Metschnikowia pulcherrima and }\end{array}$ & $\begin{array}{l}\text { are indicative for different species or species groups). These } \\
\text { analyses revealed that }>94.5 \% \text { of the sequences of bOTU_01 } \\
\text { derived from } E \text {. tasmaniensis, a potential } E \text {. amylovora } \\
\text { antagonist. The latter was represented by up to } 0.006 \% \text { of } \\
\text { the sequences. Cultivation-based analyses confirmed the } \\
\text { prevalence of E. tasmaniensis. The high abundance of native } \\
\text { potential } E \text {. amylovora antagonists likely indicates that this } \\
\text { special set of native apple blossom microbiota counteracted the } \\
\text { establishment of E. amylovora in this low-input orchard. This may } \\
\text { allow for a new approach to assess possible components of } \\
\text { synthetic apple blossom communities to mitigate fire blight } \\
\text { infections. }\end{array}$ \\
\hline $\begin{array}{l}\text { Aureobasidium pullulans. The most dominant bacterial taxon } \\
\text { (bOTU_01) was classified as Erwinia spp. To resolve sequences } \\
\text { of species within bOTU_01, we used analyses of sequence } \\
\text { variants and DNA signatures (i.e., nucleotide polymorphisms that }\end{array}$ & $\begin{array}{l}\text { Keywords: antagonists, apple blossoms, bacteriology, biological } \\
\text { control, disease control and pest management, Erwinia } \\
\text { amylovora, Erwinia tasmaniensis, fire blight, low-input orchard, } \\
\text { metabarcoding, microbiome, sub OTU-level analysis }\end{array}$ \\
\hline
\end{tabular}

The genus Erwinia (family Enterobacteriaceae) includes phytopathogenic and nonphytopathogenic bacterial species, some of which are associated with economically significant pome fruit trees. Erwinia amylovora, the causative agent of the devastating disease "fire blight", is the most important pathogen of this genus. It infects Rosaceae plants, including apple, pear, and quince. E. pyrifoliae causes fire blight on Asian (Nashi) pear and is considered to be

\footnotetext{
${ }^{\dagger}$ Corresponding author: C. Pelludat; cosima.pelludat@agroscope.admin.ch

F. Gschwend and A. Braun-Kiewnick contributed equally to the work.
}

*The $e$-Xtra logo stands for "electronic extra" and indicates that supplementary materials are published online.

The author(s) declare no conflict of interest.

(C) 2021 The American Phytopathological Society geographically restricted to Korea and Japan (Rhim et al. 1999; Shrestha et al. 2003). Epiphytic species within the genus include E. billingiae and E. tasmaniensis, which also reveal potential for use as antagonists in E. amylovora biocontrol (Jakovljevic et al. 2006; Mergaert et al. 1999).

The fire blight pathogen multiplies on the stigma after being transported to a blossom by bees or other pollinating insects and can be washed down the style into the floral nectary by water, subsequently infecting the underlying tissue (Stockwell et al. 1998). Therefore, most fire blight management strategies have focused on the reduction of inoculum in the orchard and treatments to prevent blossom infections (Norelli et al. 2003). Currently, the most effective fire blight control is the application of antibiotics such as streptomycin (Sundin et al. 2009). Due to the emergence and spread of streptomycin resistance (Chiou and Jones 1995) and increasing public concerns about using antibiotics in agriculture, all field applications of streptomycin in Switzerland were banned in 2016. 
Therefore, there is a need for alternatives to control fire blight, and biocontrol may offer such alternatives. For decades, antagonists of the fire blight pathogen have been isolated using classical cultivation and subsequent in vitro and in vivo analyses for assessing the antagonistic activity of a selected strain Mikiciński et al. (2020). In general, growth and subsequent efficacy of a biocontrol agent may vary and is dependent on the location and the conditions that may differ (Johnson and Stockwell 1998).

With the availability of new DNA-sequencing technologies and the processing of large data sets, the possibility has been provided to characterize entire microbial communities (Aleklett et al. 2014) rather than isolating and characterizing individual strains. Because of the recognition of its ecological and economical importance, plant-associated microbiota research has significantly increased over the past 10 years. Biocontrol strategies based on the microbiota and use of the microbial diversity in an environment might overcome inconsistencies experienced with applying individual organisms in biocontrol (Berg et al. 2017). Microbiota studies may assist the development of synthetic communities or they can support the development of strategies to promote already existing beneficial microflora by allowing the fostering of biocontrol agents that already exist in the community of a growing area. This might improve efficacy and consistency of the applied biocontrol agent. Initial studies performed on apple blossoms in Wisconsin and Connecticut, United States revealed specific differences in bacterial communities. Either they were dominated by members of the phyla Deinococcus-Thermus and TM7 (Shade et al. 2013) or the genus Pseudomonas and family Enterobacteriaceae (Steven et al. 2018).

To characterize a microbiota with antagonistic potential against the fire blight pathogen, an orchard with a low-input plant protection regime was selected. No fire blight incident was reported in this orchard, although the disease occurred in the immediate vicinity. The two main research goals were to (i) characterize bacterial and fungal communities in apple blossoms from varieties Ariwa, Boskoop, Idared, Milwa/Diwa, and Golden Delicious and (ii) infer explanations for the absence of fire blight infection in this orchard. Therefore, we collected apple blossoms from the stage at which they are most susceptible to E. amylovora infections and assessed bacterial and fungal communities using metabarcoding. Thus, the presented study provides the information needed for hypothesisdriven studies in fire blight protection on synthetic communities with antagonistic potential.

\section{MATERIALS AND METHODS}

Field site. Blossom samples were collected during full bloom in 2017 in an apple orchard at the Agroscope Research Station in Waedenswil, Switzerland (GPS: 47 $\left.13^{\prime} 18.1^{\prime \prime} \mathrm{N}, 8^{\circ} 40^{\prime} 38.9^{\prime \prime} \mathrm{E}\right)$. The orchard $\left(800 \mathrm{~m}^{2}\right.$ in size), with eight rows of trees and a planting distance of $4 \mathrm{~m}$ between rows and $1.5 \mathrm{~m}$ within rows, was established between 1998 and 2007 and consists of five apple varieties (i.e., Ariwa, Boskoop, Idared, Milwa/Diwa, and Golden Delicious). Golden Delicious trees were located at the borders of the orchard for pollination, while the trees of the other varieties were planted in rows. Varieties Idared and Golden Delicious have been tested in two consecutive years in E. amylovora shoot infection. Idared was classified as moderate and highly susceptible and Golden Delicious as moderate susceptible in both years (Kostick et al. 2019). The orchard had a low-input managing regime to study naturally occurring insect and mite populations. Records from 2010 to 2017 show that fertilizers and herbicides were used every year but no insecticides and other pesticides until 2015. In 2015, Myco-sin (containing 75\% sulfuric acid clay) was applied three times at $8 \mathrm{~kg} /$ ha for fire blight control. In 2016, LMA (at $20 \mathrm{~kg} / \mathrm{ha}$, potassium alum for fire blight control) was applied, as well as the fungicides Slick (1×), Flint $(1 \times)$, and Captan $(2 \times)$. Before blossom sampling in 2017, there were no pesticide treatments. This low-input orchard has no history of fire blight infection, although fire blight was present for several years in a conventional orchard in the immediate vicinity (approximately $100 \mathrm{~m}$ ) (Supplementary Fig. S1), which was eradicated in November 2016.

Blossom sample collection. To characterize the microbiota of apple blossoms, eight replicate samples consisting of 25 lateral blossoms each were collected randomly from two trees of the five varieties Ariwa, Boskoop, Idared, Milwa/Diwa, and Golden Delicious. Samples were taken at full bloom in 2017 (i.e., when 80 to $100 \%$ of the lateral blossoms were open), which represents the window of infection for the fire blight disease. Blossoms sampled met two criteria: first, petals were open and intact and, second, anthers were yellow to dark yellow but not brownish. The blossom petals were carefully removed by hand wearing gloves while the remaining blossom material was collected in plastic bags (i.e., 25 blossoms/bag). Material was kept on ice during sampling and transportation to the laboratory. Sample processing was performed the same day.

Sample processing and DNA extraction. For DNA extraction, $25 \mathrm{ml}$ of $1 \times$ buffer $\left(\mathrm{K}_{2} \mathrm{HPO}_{4}\right.$ at $2.5 \mathrm{~g} \mathrm{liter}^{-1}$ and $\mathrm{KH}_{2} \mathrm{PO}_{4}$ at $1.2 \mathrm{~g}$ liter $^{-1}$ ) was added to each plastic bag containing 25 blossoms from one sample. Bags were shaken briefly and sonicated for 1 min (37 $\mathrm{kHz}$, sweep mode, Elmasonic S $30 \mathrm{H}$ ). Blossom extracts were transferred to sterile $15-\mathrm{ml}$ centrifuge tubes and stored at $-20^{\circ} \mathrm{C}$ until DNA extraction. After thawing, extracts were centrifuged $(2,205 \times \mathrm{g})$ for $30 \mathrm{~min}$ at $4{ }^{\circ} \mathrm{C}$ and the pellet was resuspended in $2 \mathrm{ml}$ of the supernatant, of which $0.5-\mathrm{ml}$ aliquots were transferred to sterile microcentrifuge tubes and centrifuged for $10 \mathrm{~min}$ at $9,900 \times$ $g$. DNA was extracted from the resulting pellets using the BioSprint 96 DNA Plant Kit (Qiagen) according to the manufacturer's protocol. Shortly, each pellet was resuspended in $300 \mu$ l of RLT Lysis buffer and incubated for $30 \mathrm{~min}$ at $65^{\circ} \mathrm{C}$ and $1,000 \mathrm{rpm}$ in a thermomixer. After centrifugation for $5 \mathrm{~min}$ at $5,000 \times \mathrm{g}, 200 \mu \mathrm{l}$ of each supernatant was transferred to 96 deep-well plates containing isopropanol and MagAttract Suspension G (magnetic silica beads). DNA was eluted in $100 \mu \mathrm{l}$ of sterile MilliQ water and stored at $-20^{\circ} \mathrm{C}$ until further processing.

PCR reaction and sequencing. The fragment of the bacterial small subunit of the ribosomal RNA (rRNA) gene (16S rRNA) containing the variable regions V5 and V6 was amplified according to Shade et al. (2013) using the primer pair 799F (5'-AACMGGATTAGATACCCKG-3')/1115R (5'-AGGGTTGCGCTCGTTG$3^{\prime}$ ) (Chelius and Triplett 2001; Reysenbach and Pace 1995). The fungal ribosomal internal transcribed spacer (ITS) 2 was amplified using the primer pair ITS3 (5'-CAHCGATGAAGAACGYRG-3')/ ITS4 (5'-TCCTSCGCTTATTGATATGC-3') (Tedersoo et al. 2014). Primers were extended with CS1 or CS2 adapters to allow multiplexing with the Fluidigm Access Array System (Fluidigm, South San Francisco, CA, U.S.A.). PCR mixtures consisted of 1× GoTaq Flexi buffer colorless (Promega Corp.), $2.5 \mathrm{mM}$ $\mathrm{MgCl}_{2}, 0.2 \mathrm{mM}$ dNTPs, $0.2 \mu \mathrm{M}$ of each primer, GoTaq G2 (Hotstart Polymerase) at $1.25 \mathrm{U} /$ reaction, and $4 \mu \mathrm{l}$ of isolated DNA template per reaction in a $25-\mu l$ volume. PCR conditions were $2 \mathrm{~min}$ at $95^{\circ} \mathrm{C} ; 35$ cycles of $40 \mathrm{~s}$ at $94^{\circ} \mathrm{C}, 40 \mathrm{~s}$ at $58^{\circ} \mathrm{C}$, and $1 \mathrm{~min}$ at $72^{\circ} \mathrm{C}$; and a final amplification step of $10 \mathrm{~min}$ at $72^{\circ} \mathrm{C}$. The approximate length of amplification products was $335 \mathrm{bp}$ for bacteria and $400 \mathrm{bp}$ for fungi. Integrity and quality of the PCR products were analyzed on $1 \%$ agarose gels. PCR was replicated four times and qualitycontrolled replications were pooled prior to sequencing on an Illumina MiSeq platform (Génome Québec Innovation Center at the McGill University, Canada). Raw sequences were deposited in the 
NCBI Sequence Read Archive database with the accession number PRJNA609888.

Sequence processing and taxonomic classification. Sequences were processed and clustered into operational taxonomic units (OTUs) using a customized pipeline adapted from Frey et al. (2016) and Mayerhofer et al. (2017), which was mainly based on USEARCH v9 (Edgar 2010). Briefly, quality control of the sequences included, first, the removal of remaining PhiX sequences, merging of paired-end reads, and removal of primer sequences (allowing for one mismatch) using cutadapt (Martin 2011). Then, all sequences with a maximum expected error of at least 1 were discarded. Finally, sequences were clustered into operational taxonomic units (OTUs) with 97\% sequence identity along with de novo chimera removal, and targets were verified using Metaxa 2 for prokaryotic 16S (Bengtsson-Palme et al. 2015) and ITSx for eukaryotic ITS2 sequences (Bengtsson-Palme et al. 2013). Qualifying prokaryotic sequences were taxonomically assigned based on the SILVA database v123 (Quast et al. 2013) using the naïve Bayesian classifier implemented in MOTHUR v.1.36.1 (Schloss et al. 2009). The same classifier was used to compare eukaryotic sequences to a custom-made, GenBank-derived database in order to distinguish fungal from other eukaryotic sequences (Frey et al. 2016). Fungal sequences were taxonomically assigned using the same classifier but based on the UNITE database v7.2 (Nilsson et al. 2019). A bootstrap analysis was used to estimate the robustness of the taxonomic assignments on each taxonomic level. Assignments with a bootstrap value $<80 \%$ were considered as unclassified. Only sequences classified as bacteria or fungi were kept for further analyses.

Estimating microbial diversity and statistical analysis. Statistical analyses were done in $\mathrm{R}$ version 3.2.2 (R Core Team 2016). Sequencing depth was assessed by rarefaction analysis and Good's coverage. The $\alpha$ diversity was assessed as OTU richness (i.e., the number of OTUs per sample) as well as Simpson evenness and inverse Simpson indices. The inverse Simpson index indicates the effective number of OTUs in a sample, which is the number of equally abundant OTUs that correspond to the detected diversity. To correct for the different sequencing depths among samples, communities were subsampled with 10,000 iterations to the minimal sequence number. Average values for OTU richness, Simpson evenness, and inverse Simpson indices were calculated using 'summary.single' in MOTHUR v 1.36.1. Similarly, Bray-Curtis dissimilarities used for pairwise community comparisons were obtained as average values of 10,000 subsamplings using 'dist.shared' in MOTHUR v 1.36.1. The $\alpha$-diversity data were tested for normal distribution and similarity of variance among groups using Shapiro and Levene tests. Subsequently, analysis of variance (ANOVA) and pairwise Tukey's honestly significant difference were used to test for differences of $\alpha$ diversities among apple varieties. For comparisons of microbial community structures, permutational analysis of variance (PERMANOVA) was calculated using 'adonis' of the R package vegan (Oksanen et al. 2018), and the test assumption of homogeneous multivariate dispersions among groups was assessed using 'betadisper' of the same $\mathrm{R}$ package. $P$ values of multiple tests were corrected based on the Benjamini-Hochberg $P$ value adjustment method.

Sub-OTU-level classification of bacterial OTU_01 sequences. DADA2 version 1.16 (Callahan et al. 2016) was used to define sequence variants (SVs). Default parameters of DADA2 were applied with three exceptions: (i) sequences without primers were discarded, (ii) a more stringent quality control was applied with a maximum expected error of 1 instead of 2, and (iii) eukaryotic sequences were trimmed using cutadapt (Martin 2011). The last $50 \mathrm{bp}$ of forward and the last $100 \mathrm{bp}$ of reverse reads were removed due to their generally low quality. Their inclusion would have led to lower quality of the entire sequences, not allowing them to pass subsequent quality control. The first two adaptations of the DADA2 pipeline were chosen to use the same conditions for sequence quality control prior to SV definition as for OTU clustering, and the third was necessary because DADA2 separately filters forward and reverse reads. The $\alpha$ and $\beta$ diversities based on SVs were obtained as described for OTUs. To identify SVs that were associated with bacterial OTU (bOTU)_01, we mapped SVs to the bOTU_01 centroid sequence using USEARCH v9 (usearch_global) and selected SVs with a minimum sequence identity of $97 \%$ to the bOTU_01 centroid sequence.

A classification key was developed to taxonomically assign the SVs mapped to bOTU_01 as well as all sequences that clustered within bOTU_01. This classification key was based on specific nucleotide polymorphisms, and allowed us to classify bacterial species or species groups based on these signatures. First, a list of genera potentially included in bOTU_01 was generated using a BLAST search (NCBI) which yielded all genera that had an identity of at least $96 \%$ to the bOTU_01 centroid sequence. Second, all species of these genera and all species within the family Erwiniaceae were retrieved from the List of Prokaryotic Names with Standing in Nomenclature (LPSN) (Parte 2018). This generated a list with 196 species of 23 genera (Supplementary Table S1). Sequences of their type strains were then compared with the sequences within bOTU_01 for exact matches. Only 14 species of five genera revealed a perfect match with sequences within bOTU_01. These were aligned (Supplementary Fig. S2) and DNA sequence signatures that differentiated species or species groups were identified. The classification algorithm was implemented in Python version 3.5. Unique sequences included in a bOTU_01 were determined using -fastx_uniques in USEARCH v9 and aligned using Mafft v7.310 (Katoh and Standley 2013) with default parameters. The aligned sequences were then classified according to the established DNA sequence signatures.

Cultivation of Boskoop blossom isolates. Four days after sampling blossoms for the metabarconding approach, an additional eight blossom samples (each containing 25 blossoms) were collected from Boskoop trees of the low-input orchard. Petals and stems were removed and blossoms were transferred into a 50-ml Falcon tube. To each sample, $25 \mathrm{ml}$ of $1 \times$ buffer (as described above) was added. Samples were shaken for $1 \mathrm{~h}$ at $500 \mathrm{rpm}$ and vortexed for an additional $30 \mathrm{~s}$. From the supernatant of each sample, a 1-ml aliquot was transferred to a fresh 2-ml reaction tube, glycerol (40\% stock solution) was added to a final concentration of $20 \%$, and the mixture was stored at $-80^{\circ} \mathrm{C}$. DNA extraction, amplification, sequence processing, and taxonomic classification for these additional samples were performed as described above. For cultivation studies, $100 \mu \mathrm{l}$ of a $10^{-3}$ dilution from each sample was plated on King's B (KB) (King et al. 1954), lysogeny broth (LB) (Roth), and tryptic soy broth (TSB) (Oxoid) agar and incubated for 4 days at $26^{\circ} \mathrm{C}$.

Identification of Boskoop blossom isolates. The cultivated colonies of a KB plate were assigned to groups according to their morphology. Groups represented by only one colony were not further analyzed. For matrix-assisted laser desorption-ionization time-of-flight (MALDI-TOF) identification, all colonies were tested when a group consisted of two to three colonies. If groups consisted of 4 to 10 members, at least three colonies were analyzed; if there were 10 or $>10$ members, five colonies were analyzed. If MALDI-TOF did not yield an identification (cut-off score $<2$ ) of the selected members of a morphology group, the 16S rRNA gene or ITS2 was sequenced from randomly selected individual colonies of this subgroup. MALDI-TOF was performed according to 
Gekenidis et al. (2014) using a MicroFlex biotyper, and the MALDI Biotyper software (database version 4.0.0.1; Bruker Daltonics). Briefly, cell material from a colony was smeared onto a MALDI target and covered with $1 \mu \mathrm{l}$ of matrix solution ( $\alpha$-cyano-4hydroxycinnamic acid at $10 \mathrm{mg} \mathrm{ml}^{-1}$ ) dissolved in acetonitrilewater-trifluoroacetic acid (50:47.5:2.5 [vol/vol/vol]). The MALDI target was processed using the instrument's standard settings for bacteriological classification.

For $16 \mathrm{~S}$ rRNA or ITS2 amplification, a crude DNA extract was prepared by suspending colonies in $100 \mu$ l of KAWA buffer (Kawasaki 1990), followed by vortexing, incubation at $85^{\circ} \mathrm{C}$ for 20 min, and centrifugation at $12,000 \times g$ for $1 \mathrm{~min}$. The supernatant was used as PCR template. The ITS2 PCR was performed as described above. For $16 \mathrm{~S}$ rRNA gene amplification, the universal primers fD1 (5'-AGAGTTTGATCCTGGCTCAG-3') and rP2 (5' ACGGCTACCTTGTTACGACTT-3') (Weisburg et al. 1991) and the Hotstar Taq DNA polymerase (Qiagen) were used. Amplification conditions were $15 \mathrm{~min}$ at $95^{\circ} \mathrm{C} ; 35$ cycles of $30 \mathrm{~s}$ at $95^{\circ} \mathrm{C}$, $30 \mathrm{~s}$ at $56^{\circ} \mathrm{C}$, and $1.5 \mathrm{~min}$ at $72^{\circ} \mathrm{C}$; followed by a final extension of $10 \mathrm{~min}$ at $72^{\circ} \mathrm{C}$. DNA sequencing was performed by Microsynth AG (Balgach, Switzerland) and sequences were identified by aligning type strain sequences retrieved from LPSN and close matches of BLAST searches (NCBI).

\section{RESULTS}

Apple varieties and their blossom associated microbiota. Amplicon sequencing of the V5 and V6 regions of the bacterial 16S rRNA and the fungal ITS2 resulted in a total of 1.5 million reads for bacteria and 1.2 million reads for fungi. The reads were assigned to 588 bacterial and 746 fungal OTUs using a $97 \%$ sequence identity cut-off. A Good's coverage of $100 \%$ revealed extensive sequencing depths (Table 1).

Microbial communities in the apple blossoms of the varieties Ariwa, Boskoop, Idared, Milwa/Diwa, and Golden Delicious (see Material and Methods, field site) were determined using $\alpha$ - and $\beta$-diversity metrics. The $\alpha$ diversity was assessed as the number of
OTUs in a sample (i.e., the OTU richness), the distribution of OTU abundances (i.e., Simpson evenness), and the combination thereof (i.e., the inverse Simpson index). Among varieties, significant differences for bacterial communities were detected for the indices Simpson evenness (ANOVA, $F=3.8, P=0.017$ ) (Supplementary Table S2) and inverse Simpson $(F=6.4, P=0.002)$ (Supplementary Table S2). Pairwise comparisons revealed that these differences of bacterial $\alpha$ diversities were caused by the variety Boskoop, which had an increased inverse Simpson index as compared with the other varieties (Fig. 1A). The $\beta$ diversity was determined using pairwise community comparisons based on Bray-Curtis dissimilarity. Similarly to $\alpha$ diversity, the bacterial $\beta$ diversity (Supplementary Fig. S3) was significantly different among varieties (PERMANOVA, Pseudo- $F=7.7, P=0.0002$ ) (Supplementary Table S3). Again, this difference was driven by the bacterial communities of Boskoop blossoms (PERMANOVA, $P<0.016$ ) (Supplementary Table S3).

Fungal communities did not significantly differ among varieties in $\alpha$ diversities (ANOVA, $P=0.2$ ) (Supplementary Table S2; Fig. $1 \mathrm{~B}$ ) but did in terms of $\beta$ diversity (PERMANOVA, Pseudo- $F=$ 2.2, $P=0.0001$ ) (Supplementary Table S3). Pairwise comparisons revealed significant differences of fungal communities between Golden Delicious and the varieties Ariwa, Idared, and Milwa/Diwa (Supplementary Table S3). Furthermore, fungal communities of Milwa/Diwa and Ariwa blossoms significantly differed in their $\beta$ diversity.

Dominant bacterial and fungal taxa. The 10 most abundant bOTUs and fungal OTUs (fOTUs) accounted, on average, for 97.6 and $71.6 \%$, respectively, of the relative abundance per sample (Supplementary Fig. S4). Thus, the remaining 578 bOTUs and 736 fOTUs represented only 2.4 and $28.4 \%$, respectively, of the mean relative abundance per sample (Fig. 2A and B). Bacterial communities of all varieties were dominated by bOTU_01 that was assigned to Erwinia sp. (bootstrap value of 96\%) (Table 2). On average, bOTU_01 had a mean relative abundance of $81.6 \%$, with the variety Boskoop showing a significantly lower abundance (67.3\%; ANOVA, $F=8.5, P<0.0001$ ) (Supplementary Fig. S5).

TABLE 1

List of samples, operational taxonomic unit (OTU) numbers, number of sequences per sample, sequencing depth, and the ubiquitous bacterial and fungal OTUs (bOTU and fOTU, respectively)

\begin{tabular}{lcc}
\hline Parameters $^{\mathrm{a}}$ & Bacteria & Fungi \\
\hline Number of samples & 40 & 40 \\
\hline Number of OTUs & 588 & 746 \\
\hline Number of sequences & $1,555,631$ & $1,188,229$ \\
\hline Mean number of sequences per sample \pm STD & $38,891 \pm 6,397.2$ & $29,706 \pm 11,653.9$ \\
\hline Mean number of OTUs per sample \pm STD & $86 \pm 37.1$ & $100 \pm 33.8$ \\
\hline Mean Good's coverage per sample \pm STD & $1.0 \pm 0.00$ & $1.0 \pm 0.00$ \\
\hline Mean sequence lengths (nucleotides) \pm STD & $300 \pm 3.0$ & $318 \pm 34.2$ \\
\hline Number of OTUs that occur in all samples (ubiquitous OTUs) & 4 & 6 \\
\hline Ubiquitous OTUs and their taxonomic assignment & bOTU_01 Erwinia sp. & fOTU_01 Metschnikowia pulcherrima \\
\hline & bOTU_02 Rosenbergiella sp. & fOTU_02 Podosphaera leucotricha \\
\hline & bOTU_03 Pseudomonas sp. & fOTU_03 Aureobasidium pullulans \\
\hline & bOTU_16 Oxalobacteraceae & fOTU_04 Pleosporales \\
\hline
\end{tabular}


The bOTU_01 was followed by bOTU_02 (Rosenbergiella sp., bootstrap value of $83 \%$ ) (Table 2) that covered, on average, $12.7 \%$ of the mean relative abundance. With $28.4 \%$, the blossoms of Boskoop showed a significantly (ANOVA, $F=13.4, P<0.0001$ ) (Supplementary Fig. S5) increased abundance of bOTU_02 while this bOTU did not exceed a mean relative abundance of $8.8 \%$ in the other varieties. Similarly, bOTU_03 (Pseudomonas sp., 100\%) covered, on average, $1.8 \%$ of bacterial sequences. All other bOTUs covered, on average, $<0.5 \%$ of bacterial sequences (Fig. 2A).

The most dominant component of fungal communities was fOTU_01, which was assigned to the species Metschnikowia pulcherrima (bootstrap value of $99 \%$ ) (Table 3). Its mean relative abundance per variety ranged from 19.9 to $37.6 \%$, with an average of $28.2 \%$ (Fig. 2B). In Golden Delicious blossoms, fOTU_01 had a mean relative abundance of $19.9 \%$, which was similar to that of fOTU_04 (Pleosporales, bootstrap value of 97\%) with $20.0 \%$ (Supplementary Fig. S6). The fOTU_02 had an identical sequence with Podosphaera leucotricha (bootstrap value of $100 \%$ ), which is the causal agent of apple powdery mildew, and a mean relative abundance of 9.3 and $11.1 \%$ in Boskoop and Idared, respectively. In Milwa/Diwa blossoms, fOTU_02 had a mean relative abundance of $21.8 \%$ and, therefore, was the second most dominant fungal taxon in the blossoms of this apple variety. The third most abundant fOTU was fOTU_03, which was assigned to Aureobasidium pullulans (bootstrap value of $100 \%$ ), with an average relative abundance of $8.9 \%$.

In summary, the community compositions in the analyzed apple blossoms of all five varieties were dominated by only a few bacterial and fungal OTUs (Supplementary Fig. S4). This was particularly true for the bacterial community and bOTU_01 that, on average, had an abundance of $81.6 \%$.
Species classifications of bOTU_01 sequences. Sequence clustering into OTUs was based on a sequence identity threshold of 97\%. The bOTU_01 consisted of 189,871 different sequences and was classified as Erwinia sp., with a bootstrap value of $96 \%$. This OTU was of particular interest in this study because it most likely contained the fire-blight-causing agent $E$. amylovora and, therefore, more in-depth analyses were applied for this OTU by assessing unique sequences and SVs (using DADA2) within bOTU_01. Before this analysis, the congruence of SVs and OTUs was assessed at the entire community level, which yielded highly correlated $\alpha$ $\left(\rho_{\text {Bacteria }} \geq 0.87, \rho_{\text {Fungi }} \geq 0.60\right)$ and $\beta\left(\rho_{\text {Bacteria }}=0.90, \rho_{\text {Fungi }}=0.89\right)$ diversities, with the same patterns of similarities among varieties (Supplementary Tables S2 and S3; Supplementary Fig. S3). Then, SVs falling within bOTU_01 were determined, which yielded six SVs. To classify these SVs, as well as all sequences clustered within the OTU, we developed, a classification key based on DNA sequence signatures (i.e., specific nucleotide polymorphisms that are indicative for different species or groups of species) (see Material and Methods). The assignment of bOTU_01 sequences according to this classification key resulted in 14 species of five genera (i.e., E. amylovora, E. tasmaniensis, E. endophytica, E. billingiae, E. rhapontici, E. persicina, E. aphidicola, E. iniecta, Siccibacter colletis, Phytobacter ursingii, Pantoea rwandensis, P. agglomerans, Buttiauxella warmboldiae, and B. izardii). The marker sequence did not allow discriminating $P$. agglomerans from $B$. izardii, as well as $P$. rwandensis from $B$. warmboldiae (Supplementary Table S1). Furthermore, E. billingiae, E. aphidicola, E. rhapontici, E. persicina, and E. iniecta could not be distinguished. Therefore, these were grouped and are referred to as Erwinia group BARPI (Fig. 3). Based on the developed classification key (Fig. 3), two SVs were classified to E. tasmaniensis

A Bacteria

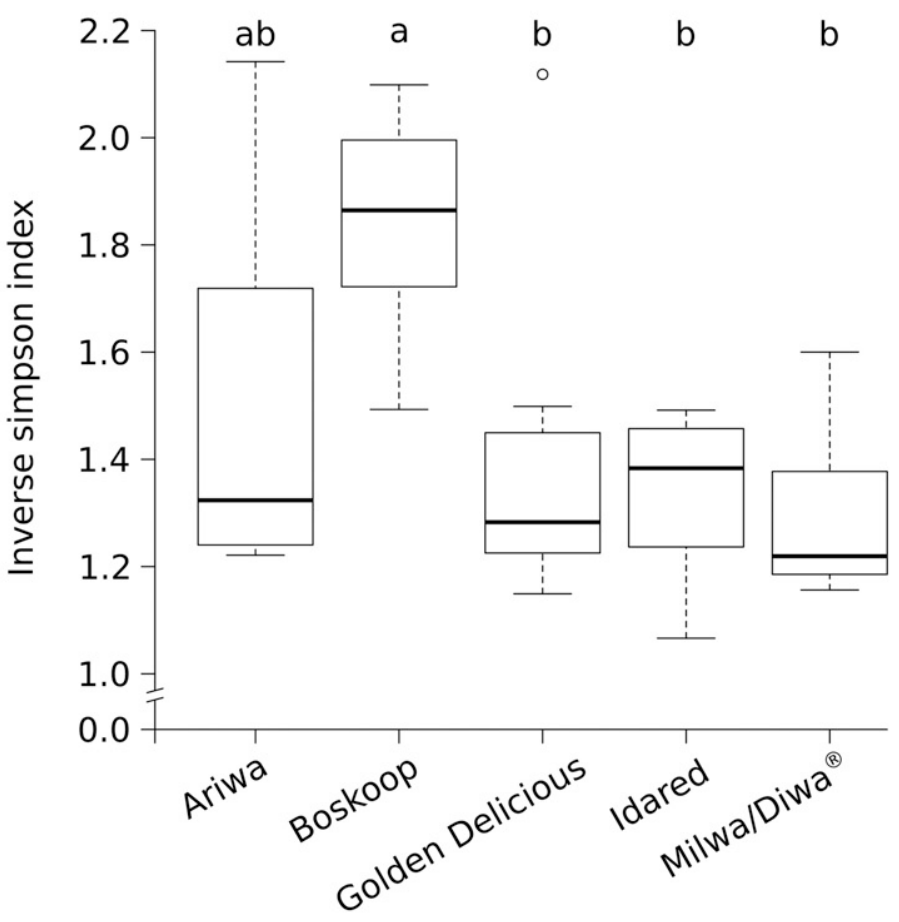

B Fungi

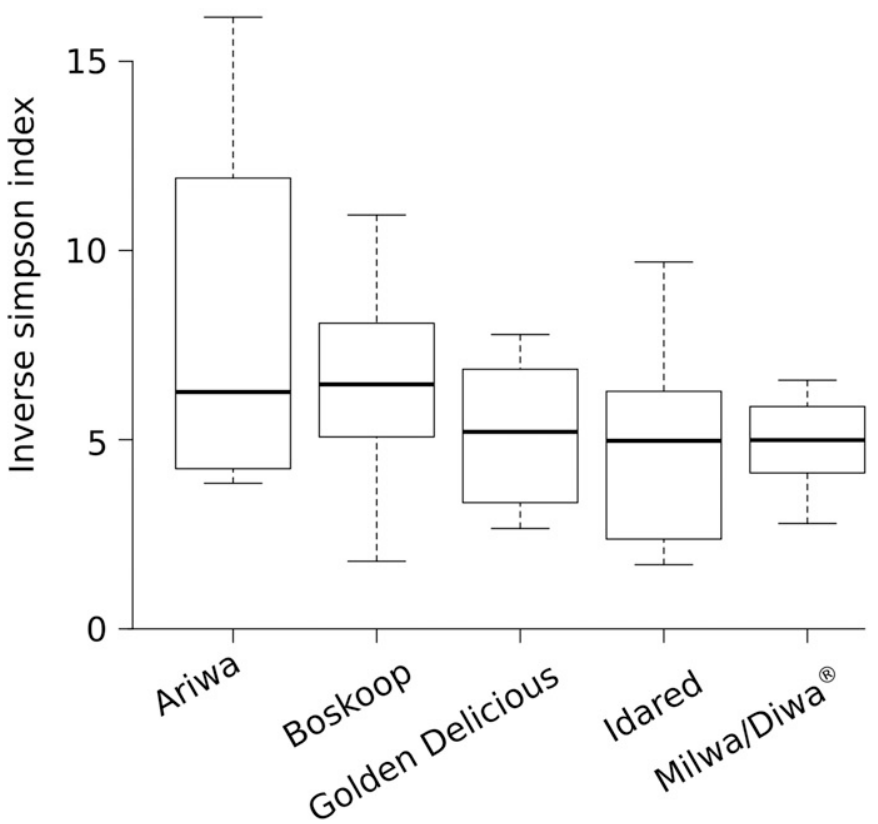

Fig. 1. A, Bacterial and B, fungal $\alpha$ diversity on apple blossoms sampled from varieties Ariwa, Boskoop, Golden Delicious, Idared, and Milwa/Diwa. Different letters indicate significant differences according to pairwise group comparisons. Analysis of variance: $F=6.4, \mathrm{df}=4, P=0.002(\mathrm{~A})$ and $F=1.9$, $\mathrm{df}=4, P=0.236(\mathrm{~B})$. 
(bSV_01 and bSV_04); one each to Erwinia group BARPI (bSV_5), E. amylovora (bSV_127), and P. agglomerans (bSV_22); and one remained unclassified (bSV_15). The E. tasmaniensis SVs 1 and 4 were most abundant and covered 96.0 and $2.5 \%$, respectively, of the abundance of bOTU_01, while the SV classified as E. amylovora covered $0.004 \%$. Highly similar results were obtained when classifying all 1,263,244 sequences within bOTU_01 according to the DNA signatures. The majority of $94.5 \%$ sequences ( $n=1,194,207$ ) were classified to E. tasmaniensis based on the DNA signatures and the most abundant sequence was identical to the one of type strain E. tasmaniensis Et1/99 isolated from apple blossoms in Tasmania. The Erwinia group BARPI included 15,767 sequences, representing $1.2 \%$ of bOTU_01. Only 75 sequences, representing $0.006 \%$, of bOTU_01 were classified as E. amylovora and 559 sequences $(0.044 \%)$ were assigned to $P$. agglomerans. In total, 52,420 sequences of bOTU_01 (4.1\%) could not be attributed to a species or species group based on the developed classification key. In addition, few sequences $(0.017 \%)$ were classified to E. endophytica, S. colletis, Phytobacter ursingii, or Pantoea rwandensis, which were not detected using the SV approach.

Cultivation based verification of the Boskoop blossom microbiota. To verify the data obtained with metabarcoding, isolates of eight Boskoop samples were cultivated on $\mathrm{KB}$ agar (Supplementary Fig. S7), yielding 239 colonies of five distinct morphology types (Table 4). The dominant morphology type A comprised 169 colonies. Using MALDI-TOF, all 39 tested colonies of type A were identified as E. tasmaniensis (scores 2.1 to 2.4). In addition, the 16S rRNA gene sequence from a subset of MALDI-

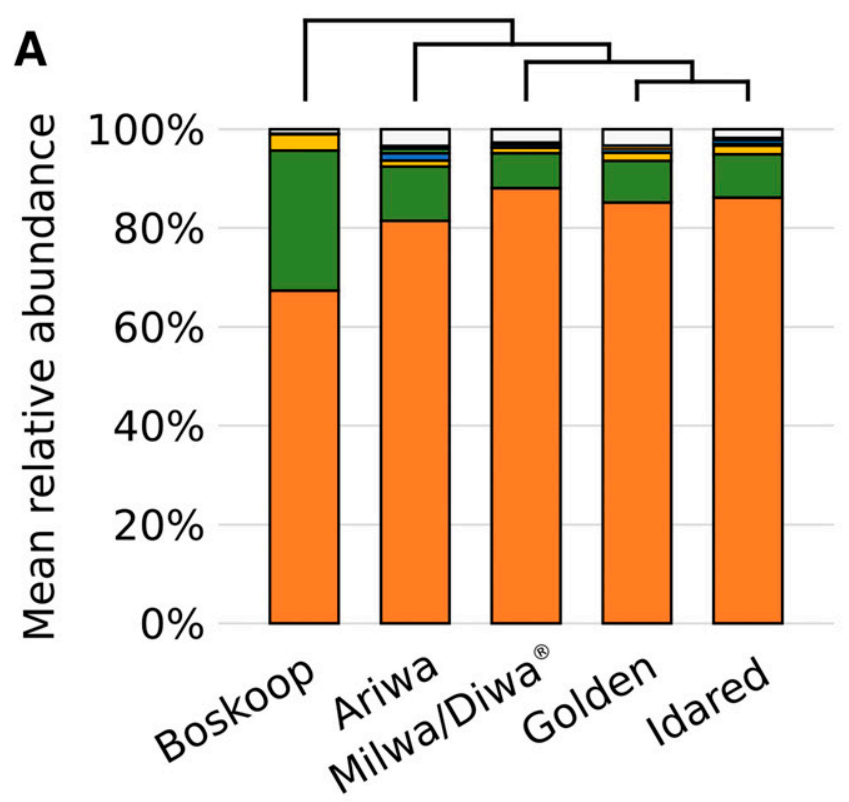
less abundant bOTUs $(\mathrm{N}=578)$
bOTU_11 - Comamonadaceae (f)
bOTU_10 - Lactobacillus ( $g$ )
$\square$ bOTU_08 - Sphingomonas $(g)$
$\square$ bOTU_16 - Oxalobacteraceae (f)
$\square$ bOTU_07 - Hymenobacter ( $g$ )
$\square$ bOTU_04 - Enterobacteriaceae (f)
$\square$ bOTU_05 - Rickettsia ( $g$ )
bOTU_03 - Pseudomonas (g)
$\square$ bOTU_02 - Rosenbergiella ( $g$ )
bOTU_01 - Erwinia (g)

$2.4 \%$

$0.1 \%$

$0.1 \%$

$0.1 \%$

$0.1 \%$

$0.2 \%$

$0.3 \%$

$0.4 \%$

$1.8 \%$

$12.7 \%$

$81.6 \%$

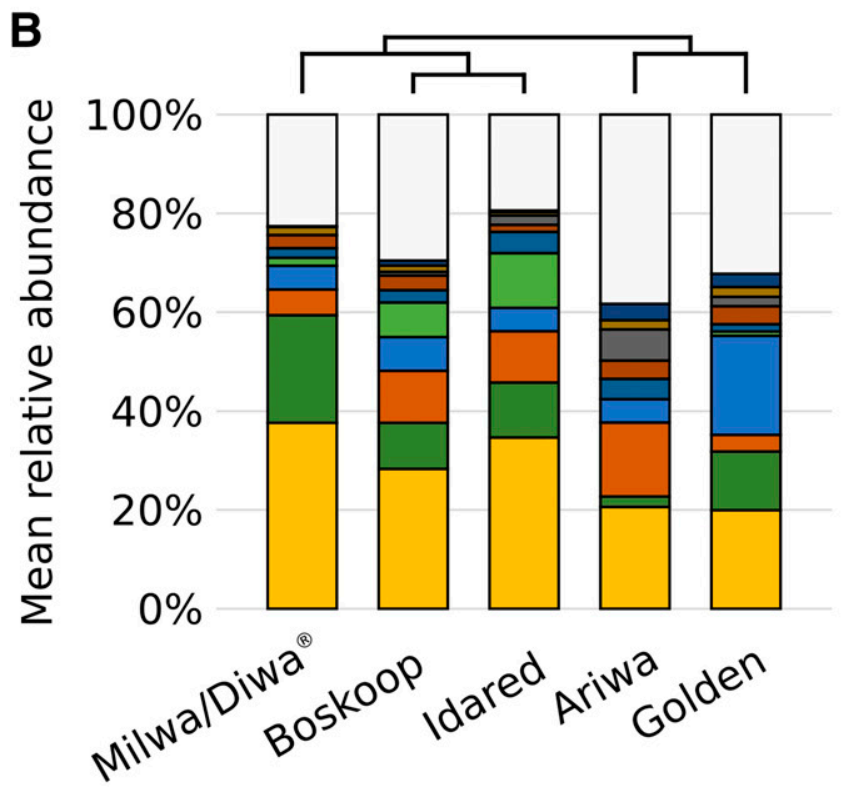

less abundant fOTUs $(\mathrm{N}=736) \quad 28.4 \%$

$1.5 \%$

$1.5 \%$

$\square$ fOTU_13 - Tremellales (o)

$2.2 \%$

$\square$ fOTU_06 - Botryosphaeriaceae (f)

$2.9 \%$

$\square$ fOTU_08 - Didymellaceae (f)

$2.9 \%$

$\square$ fOTU_09 - Capnodiales (o)

$4.1 \%$

fOTU_05 - P. lilacinum (s)

$8.2 \%$

$\square$ fOTU_04 - Pleosporales (o)

$8.9 \%$

fOTU_03 - A. pullulans (s)

$11.2 \%$

fOTU_02 - P. leucotricha (s)

$28.2 \%$

Fig. 2. Compositions of A, bacterial, and $\mathbf{B}$, fungal communities on blossoms of five apple varieties, each represented by eight samples. The 10 operational taxonomic units (OTUs) with highest mean relative abundances are colored and assigned to the species (s) or the lowest possible level (s= species, $\mathrm{g}=$ genus, $\mathrm{f}=$ family, and $\mathrm{o}=$ order); bOTU and fOTU = bacterial and fungal OTUs, respectively. Dendrograms are based on cluster analyses of mean relative abundances using Ward's clustering criterion. Fungi include Purpureocillium lilacinum, Aureobasidium pullulans, Podosphaera leucotricha, and Metschnikowia pulcherrima. 
TOF-identified E. tasmaniensis isolates had the highest identity (>99\%) to E. tasmaniensis ET1/99 (NR_074869.1) and perfectly matched to the signatures in the developed classification key (Fig. 3 ). The second most abundant colony morphology (B, 39 colonies) was identified as Rosenbergiella sp. based on the 16S rRNA gene sequence. Colony morphology C (18 colonies) (Table 4) was detected in four samples and identified as M. pulcherrima (C) based on the ITS2 sequence (CP034461.1, MN913467.1).

\section{DISCUSSION}

Fire blight was first reported in 1780 in North America, from where it spread to other parts of the world (e.g., Europe and the Mediterranean region and, recently, East Asia) (Myung et al. 2016; Park et al. 2016; van der Zwet and Bonn 1999). In addition to the cultivation of less susceptible apple varieties, the treatment of blossoms with microbial antagonists that suppress establishment and growth of E. amylovora on floral tissue is an appealing alternative to the application of chemical pesticides such as antibiotics. However, the efficacy of a biocontrol agent varies greatly depending on location and year (Johnson and Stockwell 1998). With the availability of new DNA technologies, it is possible to analyze microbial communities in a cultivation-independent manner aimed at understanding their ecological functions and providing opportunities in disease control (Berg et al. 2017; Poudel et al. 2016).

The study presented here revealed that the microbiota of apple blossoms is dominated by only a few bacterial and fungal species and that the apple variety, with the exception of Boskoop, had little effect on the community structure (Figs. 1 and 2; Supplementary Fig. S3). In large agreement with our results, Steven et al. (2018) have reported no effect of the apple varieties Braeburn, McIntosh, and Sunrise on the bacterial community structures.

The dominating taxon in this study, bOTU_01, was assigned to the genus Erwinia (Fig. 2). Nevertheless, the studied orchard had no fire blight record and showed no symptoms. Therefore, we analyzed the 1,263,244 sequences of bOTU_01 in greater detail. The majority $(n=1,194,207)$ matched the partial $16 \mathrm{~S}$ rRNA gene sequence

TABLE 2

The 10 bacterial operational taxonomic units (bOTUs) with highest mean of relative abundance (MRA) ${ }^{a}$

\begin{tabular}{|c|c|c|c|c|}
\hline bOTU & $\begin{array}{c}\text { MRA } \\
(\%)\end{array}$ & $\begin{array}{l}\text { Marker length } \\
\text { (bp) }\end{array}$ & $\begin{array}{l}\text { Taxonomic assignment, } \\
\text { bootstrap value }\end{array}$ & Defined Erwinia amylovora antagonists (reference) \\
\hline bOTU_01 & 81.6 & 300 & Erwinia (g), 96 & E. tasmaniensis (Jakovljevic et al. 2006) \\
\hline \multirow[t]{3}{*}{ bOTU_03 } & 1.8 & 300 & Pseudomonas (g), 100 & Pseudomonas fluorescens A506* (Wilson and Lindow 1993) \\
\hline & $\ldots$ & $\ldots$ & $\ldots$ & P. fluorescens EPS62e (Pujol et al. 2005) \\
\hline & $\ldots$ & $\ldots$ & ... & P. graminis 49M (Mikiciński et al. 2016) \\
\hline bOTU_05 & 0.4 & 302 & Rickettsia (g), 100 & $\ldots$ \\
\hline bOTU_04 & 0.3 & 300 & Enterobacteriaceae (f), 100 & $\ldots$ \\
\hline bOTU_07 & 0.2 & 295 & Hymenobacter (g), 100 & $\ldots$ \\
\hline bOTU_16 & 0.1 & 301 & Oxalobacteraceae (f), 100 & $\ldots$ \\
\hline
\end{tabular}

a Abbreviations: $g=$ genus and $f=$ family; * indicates commercialized.

TABLE 3

The 10 fungal OTUs (fOTUs) with highest mean of relative abundance (MRA) ${ }^{a}$

\begin{tabular}{lcccl}
\hline fOTU & MRA (\%) & Marker length (bp) & Taxonomic assignment, bootstrap value & Defined E. amylovora antagonists (reference) \\
\hline fOTU_01 & 28.2 & 215 & Metschnikowia pulcherrima (s), 99 & M. pulcherrima (Seibold et al. 2004) \\
\hline fOTU_02 & 11.2 & 289 & Podosphaera leucotricha (s), 100 & $\ldots$ \\
\hline fOTU_03 & 8.9 & 303 & Aureobasidium pullulans (s), 100 & A. pullulans ${ }^{\star}$ (Kunz 2004) \\
\hline fOTU_04 & 8.2 & 299 & Pleosporales (o), 97 & $\ldots$ \\
\hline fOTU_05 & 4.1 & 309 & Purpureocillium lilacinum (s), 100 & $\ldots$ \\
\hline fOTU_09 & 2.9 & 297 & Capnodiales (o), 100 & $\ldots$ \\
\hline fOTU_08 & 2.9 & 303 & Didymellaceae (f), 100 & $\ldots$ \\
\hline fOTU_06 & 2.2 & 307 & Botryosphaeriaceae (f), 100 & $\ldots$ \\
\hline fOTU_13 & 1.5 & 274 & Tremellales (o), 100 & $\ldots$ \\
\hline fOTU_18 & 1.5 & 294 & Pseudorotiaceae (f), 100 & \\
\hline
\end{tabular}

a Abbreviations: $\mathrm{s}=$ species, $\mathrm{g}=$ genus, $\mathrm{f}=$ family, and $\mathrm{o}=$ order; ${ }^{*}$ indicates commercialized. 


\begin{tabular}{|c|c|c|c|c|c|c|c|c|c|c|}
\hline \multirow{3}{*}{ Position } & \multirow{3}{*}{$\begin{array}{l}\infty \\
\infty \\
-\infty \\
\leftarrow-\end{array}$} & \multirow{3}{*}{ மீ) } & \multirow{3}{*}{$\begin{array}{l}O-\bar{N} N \mathbb{N} \\
G C T \quad T\end{array}$} & \multirow{3}{*}{$\begin{array}{l}\text { D } \\
\text { C } \\
\end{array}$} & \multirow[b]{2}{*}{$\stackrel{N}{\simeq}$} & & \multicolumn{2}{|c|}{ OTU } & \multicolumn{2}{|c|}{ SVs } \\
\hline & & & & & & & Sequences & in $\%$ & Sequences & in $\%$ \\
\hline & & & & & $\mathrm{C}$ & Erwinia tasmaniensis & $1,194,207$ & $94.535 \%$ & 947,572 & $98.545 \%$ \\
\hline & G GC & & & & C & Erwinia group BARPI* & 15,767 & $1.248 \%$ & 12,276 & $1.277 \%$ \\
\hline & & $\mathrm{T} G \mathrm{C}$ & G C T T & $Y$ & $T$ & Erwinia endophytica & 49 & $0.004 \%$ & 0 & $0.000 \%$ \\
\hline & & & & C & C & Pantoea $n$ wandensis ${ }^{\star \star}$ & 46 & $0.004 \%$ & 0 & $0.000 \%$ \\
\hline & A C T & T: $\mathrm{T}$ & GCT T & $\mathrm{T}$ & $\mathrm{C}$ & Pantoea agglomerans ${ }^{\star \star \star}$ & 559 & $0.044 \%$ & 581 & $0.060 \%$ \\
\hline & & & & & & Unclassified & 52,420 & $4.150 \%$ & 1,096 & $0.114 \%$ \\
\hline & & & & & & Sequences in bOTU_01 & $1,263,244$ & $100.000 \%$ & 961,563 & $100.000 \%$ \\
\hline
\end{tabular}

Fig. 3. Classification key used to assign sequences of bacterial operational taxonomic unit (bOTU)_01 as well as sequence variants (SVs) within bOTU_01 to different bacterial species. The bOTU_01 contains 1,263,244 sequences that were classified to seven species and one species group (Erwinia BARPI) based on DNA sequence signatures as defined in the methods. The Erwinia group BARPI (*) includes five species (i.e., Erwinia billingiae, E. aphidicola, E. rhapontici, E. persicina, and E. iniecta). Pantoea rwandensis $\left({ }^{*}\right)$ and Buttiauxella warmboldiae, as well as $P$. agglomerans $\left({ }^{\star \star \star}\right)$ and $B$. izardii, cannot be discriminated based on the marker sequences (Supplementary Table S3). Ambiguous nucleotides are indicated following the code of the International Union of Pure and Applied Chemistry (IUPAC) (i.e., R corresponding to $A$ or $G$ and $Y$ to $C$ or $T$ ). Positions of DNA sequence signatures correspond to the positions within the alignment provided in the supplements (Supplementary Fig. S2).

TABLE 4

All colony morphologies of isolates obtained from Boskoop blossoms with their identification and abundance ${ }^{a}$

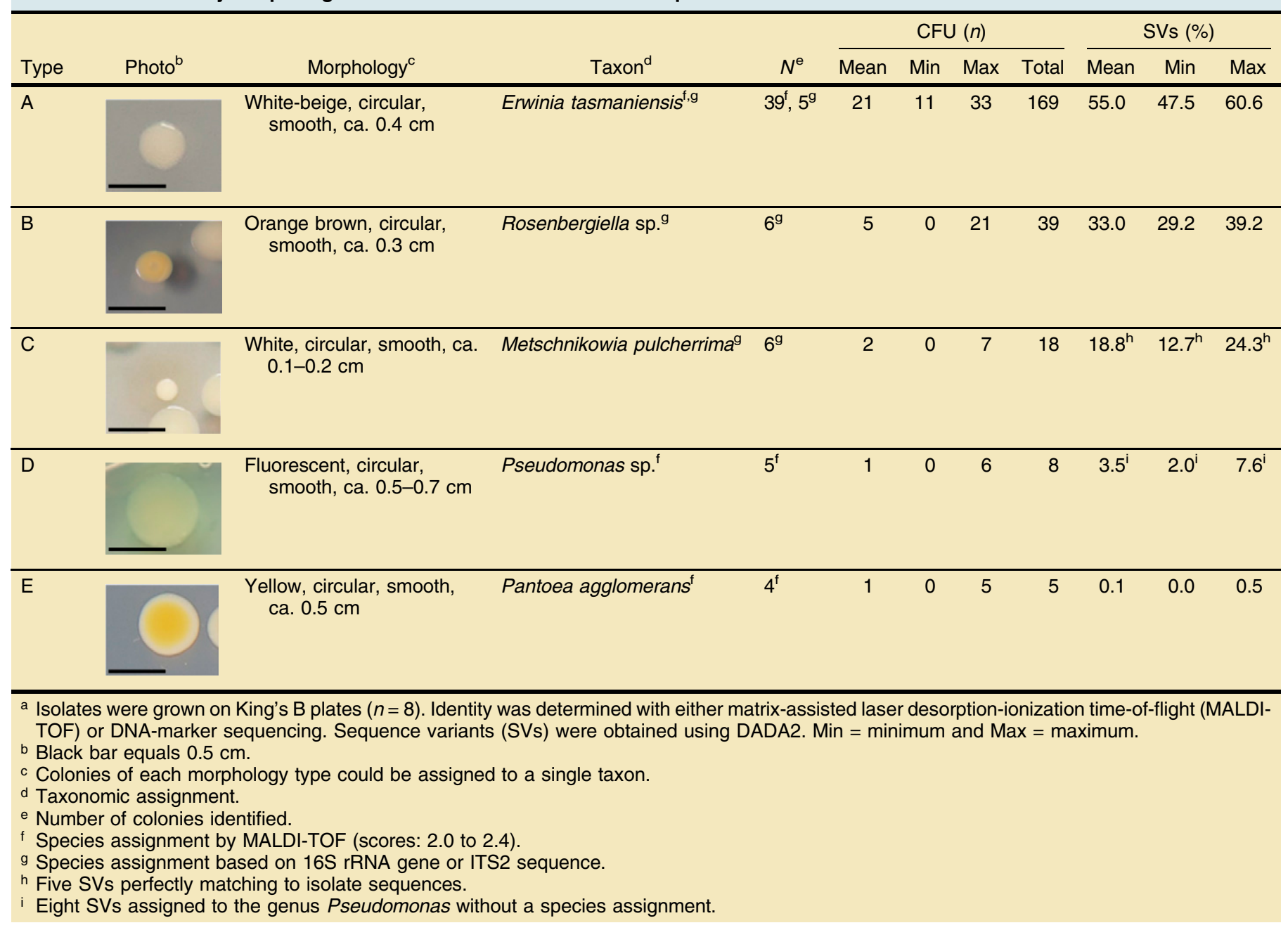


of type strain of E. tasmaniensis Et1/99 (Fig. 3), which we also obtained when using an algorithm to build SVs. Interestingly, two $\mathrm{SV}$ s were classified as E. tasmaniensis. Although the most abundant $\mathrm{SV}$ was identical to the E. tasmaniensis type strain, the other one had a single substitution of the first base pair. This substitution was observed in all samples and was present in neither the reference sequences nor the 100 best BLAST results, indicating a systematic but nonbiological origin of this SV. More species within bOTU_01 were identified based on the DNA signatures when using all sequences within bOTU_01 as compared with the SV approach. All of these species (i.e., E. endophytica, S. colletis, P. ursingii, and $P$. rwandensis) had low abundances $(\leq 0.007 \%$ of bOTU_01 sequences), which may explain that these were either erroneous sequences introduced during metabarcoding or extremely rare species. A rarely detected species in both approaches was $E$. amylovora, which indicated its presence in the studied orchard despite the absence of fire blight symptoms.

The dominant presence of E. tasmaniensis and presence of Rosenbergiella sp. as well as $M$. pulcherrima in the low-input orchard was confirmed in a cultivation-based approach. Sequencing of the 16S rRNA gene as well as the protein-based analysis using MALDI-TOF identified the dominant colony morphology on KB plates as E. tasmaniensis. Neither the cultivation on TSB and LB plates (Supplementary Fig. S8) nor an extended incubation for 10 days at room temperature displaced E. tasmaniensis as the dominant CFU on the plates. E. tasmaniensis has been first described in 2006. The type strain Et1/99 but also strain Et2/99 have been isolated as the dominant bacteria present in apple and pear flowers in Australia (Tasmania and Knoxfield, Victoria). The inoculation of immature pear or apple seedlings with these isolates has not resulted in necrotic symptoms. Thus, this species has been considered not pathogenic for the common fire blight hosts apple and pear (Geider et al. 2006). Indeed, despite the high accumulation of E. tasmaniensis in the investigated Swiss orchard, no visible disease symptoms on blossoms or tree shoots were observed. An E. tasmaniensis isolate from Germany has been included in the study of Jakovljevic et al. (2008) and two more German isolates and two from South Africa in the report of Wensing et al. (2011) but the occurrence as dominant species in apple blossoms has only been reported from Australia. Further studies will have to show how widespread this Erwinia sp. is in the apple-growing regions of Switzerland and Europe. The same applies to the largely unknown genus Rosenbergiella (family Enterobacteriaceae), to which the second most dominant bacterial bOTU_02 of the apple blossoms was assigned. Rosenbergiella nectarea has been isolated from blossom nectar of Amygdalus communis (almond) and Citrus paradisi (grapefruit) in northern Israel and was first described in 2013 (Halpern et al. 2013). Only 559 sequences could be assigned to $P$. agglomerans, which is known to be an effective colonizer of apple blossoms (Pusey and Curry 2004). Sequences of bOTU_01 and bOTU_02 were assigned to the family Enterobacteriaceae (class: Gammaproteobacteria, phylum: Proteobacteria). The third most dominant bOTU, bOTU_03, was assigned to Pseudomonas (class: Gammaproteobacteria, phylum: Proteobacteria) with a relative abundance of $1.8 \%$ only. Steven et al. (2018) have detected a bOTU assigned to Pseudomonas as the dominant taxon on stigmata and a negative correlation between Pseudomonas and Enterobacteriaceae, implying a niche exclusionary relationship between these taxa. Very different dominating bacterial taxa (i.e., members of Deinococcus-Thermus (Class: Deinococci, Phylum: Deinococcus-Thermus) and TM7 have been detected in Gala apple blossoms of an orchard in Wisconsin (Shade et al. 2013). Nonetheless, the PCR applied by Shade et al. (2013) were also used in our survey, excluding a primer bias as cause for the differences, although this cannot exclude possible bias due to DNA preparation (e.g., partially lysed spore-forming bacteria or loss of DNA during preparation). However, the consistency of metagenome- and cultivation-based results corroborated the dominance of E. tasmaniensis in the apple blossoms. Further surveys covering larger geographic areas and more apple varieties are necessary to explore the differences in the dominant members of the apple blossom microbiomes and to identify contributing factors.

bOTU_05, with a mean relative abundance of only $0.4 \%$ (Fig. 2A), was assigned to the genus Rickettsia (Table 2), which includes obligate intracellular parasites or symbionts of many arthropods (Perlman et al. 2006). Most likely, Rickettsia sequences are detected because small arthropods or their traces were sampled along with the apple blossoms. In addition, bOTU17, with a relative mean abundance of $0.03 \%$ (and thus not listed in the results), is assigned to Buchnera aphidicola, the primary endosymbiont of aphids (Baumann et al. 1995).

The analysis of the fungal community in the same apple blossoms showed a higher diversity compared with the bacterial microbiota. The 736 less-abundant fOTUs had, on average, a relative abundance of $28.4 \%$ (Fig. 2B). Within the 10 fOTUs with highest mean relative abundance, fOTU_02 ( $P$. leucotricha, the causative agent of apple powdery mildew) was the second most abundant fOTU, most probably because no plant protection products had been applied in the orchard before sampling. fOTU_01 and fOTU_03, assigned to M. pulcherrima and A. pullulans, respectively, covered $30 \%$ of all fungal sequences. Strains of $M$. pulcherrima have mainly been known for their potential against postharvest pathogens (Piano et al. 1997 ) but are also capable of inhibiting the growth of E. amylovora (Duffy et al. 2006; Seibold et al. 2004, 2006).Two strains of A. pullulans have been reported as active ingredients of a biocontrol product against fire blight (Kunz 2004). Thus, in the investigated low-input apple orchard, potential E. amylovora fungal antagonists dominate the communities in apple blossoms of all five varieties. This may explain why E. amylovora was never able to establish a disease-causing population in the studied orchard, though phenotypically present in the immediate vicinity (Supplementary Fig. S1).

In the studied orchard, an A. pullulans-based product could be favorable for fire blight control, because this would mimic an already present native fire blight antagonist that successfully established in the blossom under the given environmental conditions. Previous studies on bacterial fire blight antagonist have focused on genus Pseudomonas and members of the genus Pantoea (family Enterobacteriaceae), with commercially available strains Pseudomonas fluorescens A506 (Wilson and Lindow 1993), Pantoea agglomerans C9-1 (Ishimaru 1988), P. agglomerans $\mathrm{P} 10 \mathrm{c}$ (Vanneste et al. 2006; Smits et al. 2015), and P. agglomerans E325 (Braun-Kiewnick et al. 2011; Pusey et al. 2011). In addition, Bacillus subtilis QST 713 (Aldwinckle et al. 2002) is also available as a commercial product. However, none of these bacterial biocontrol strains corresponded to a genus that dominated the native bacterial community in the blossoms analyzed in the present study. In view of the niche exclusion relationship between members of Enterobacteriaceae and various taxa, the use of Pseudomonas- or Bacillus-based products might even have an adverse impact on fire blight control.

High-throughput sequencing technologies allow for cultivationindependent investigations at a high resolution and sensitivity. The detection of E. amylovora sequences in the studied orchard was only possible with a sequencing depth achieved by high-throughput sequencing. Furthermore, analyses of SVs were necessary to differentiate sequences of phytopathogenic and nonphytopathogenic Erwinia spp., because they were clustered within the same OTU at 97\% sequence identity. Specific DNA sequence signatures can be 
used to differentiate and accurately assign metabarcodes at a low taxonomic level. Metabarcoding enables the assessment of microbial communities, including bacteria and fungi, on sample sites with a unique character. This yields information needed for the assembly of synthetic communities that best match or complement naturally occurring antagonists in apple blossoms of a defined area and its given environmental conditions.

\section{ACKNOWLEDGMENT}

We thank E. Eugster Meier and B. Guggenbühl for initiating the Agroscope Research Program MikBioDiv; the Fruit-Growing Extension Research Group for maintaining the orchards; our colleagues for information on the fire blight susceptibility of apple varieties, DNA analysis, helpful discussion, and reading of the manuscript; and A. Wensing from the Julius-Kühn Institute in Dossenheim, Germany for detailed information on E. tasmaniensis.

\section{LITERATURE CITED}

Aldwinckle, H. S., Bhaskara Reddy, M. V., and Norelli, J. L. 2002. Evaluation of control of fire blight infection of apple blossoms and shoots with SAR inducers, biologicals agents, a growth regulator, copper compounds, and other materials. Acta Hortic. 590:325-331.

Aleklett, K., Hart, M., and Shade, A. 2014. The microbial ecology of flowers: An emerging frontier in phyllosphere research. Botany 92:253-266.

Baumann, P., Baumann, L., Lai, C. Y., Rouhbakhsh, D., Moran, N. A., and Clark, M. A. 1995. Genetics, physiology, and evolutionary relationships of the genus Buchnera: Intracellular symbionts of aphids. Annu. Rev. Microbiol. 49:55-94.

Bengtsson-Palme, J., Hartmann, M., Eriksson, K. M., Pal, C., Thorell, K., Larsson, D. G. J., and Nilsson, R. H. 2015. METAXA2: Improved identification and taxonomic classification of small and large subunit rRNA in metagenomic data. Mol. Ecol. Resour. 15:1403-1414.

Bengtsson-Palme, J., Ryberg, M., Hartmann, M., Branco, S., Wang, Z., Godhe, A., De Wit, P., Sánchez-García, M., Ebersberger, I., and de Sousa, F. 2013. Improved software detection and extraction of ITS1 and ITS2 from ribosomal ITS sequences of fungi and other eukaryotes for analysis of environmental sequencing data. Methods Ecol. Evol. 4:914-919.

Berg, G., Köberl, M., Rybakova, D., Müller, H., Grosch, R., and Smalla, K. 2017. Plant microbial diversity is suggested as the key to future biocontrol and health trends. FEMS Microbiol. Ecol. 93:fix050.

Braun-Kiewnick, A., Lehmann, A., Smits, T. H. M., Duffy, B., and Dreo, T. 2011. Environmental monitoring of Pantoea agglomerans strain E325 in Swiss orchards. Acta Hortic. 896:425-430.

Callahan, B. J., McMurdie, P. J., Rosen, M. J., Han, A. W., Johnson, A. J. A., and Holmes, S. P. 2016. DADA2: High-resolution sample inference from Illumina amplicon data. Nat. Methods 13:581-583.

Chelius, M. K., and Triplett, E. W. 2001. The diversity of Archaea and Bacteria in association with the roots of Zea mays L. Microb. Ecol. 41:252-263.

Chiou, C. S., and Jones, A. L. 1995. Expression and identification of the strA-strB gene pair from streptomycin-resistant Erwinia amylovora. Gene 152:47-51.

Duffy, B., Vogelsanger, J., Schoch, B., and Holliger, E. 2006. Biocontrol of Erwinia amylovora using a commercial yeast strain mixture. Acta Hortic. 704:363-366.

Edgar, R. C. 2010. Search and clustering orders of magnitude faster than BLAST. Bioinformatics 26:2460-2461.

Frey, B., Rime, T., Phillips, M., Stierli, B., Hajdas, I., Widmer, F., and Hartmann, M. 2016. Microbial diversity in European alpine permafrost and active layers. FEMS Microbiol. Ecol. 92:fiw018.

Geider, K., Auling, G., Du, Z., Jakovljevic, V., Jock, S., and Völksch, B. 2006. Erwinia tasmaniensis sp. nov., a non-phytopathogenic bacterium from apple and pear trees. Int. J. Syst. Evol. Microbiol. 56:2937-2943.

Gekenidis, M.-T., Studer, P., Wüthrich, S., Brunisholz, R., and Drissner, D. 2014. Beyond the matrix-assisted laser desorption ionization (MALDI) biotyping workflow: In search of microorganism-specific tryptic peptides enabling discrimination of subspecies. Appl. Environ. Microbiol. 80:4234-4241.

Halpern, M., Fridman, S., Atamna-Ismaeel, N., and Izhaki, I. 2013. Rosenbergiella nectarea gen. nov., sp. nov., in the family enterobacteriaceae, isolated from floral nectar. Int. J. Syst. Evol. Microbiol. 63:4259-4265.
Ishimaru, C. A. 1988. Multiple antibiotic production by Erwinia herbicola Phytopathology 78:746-750.

Jakovljevic, V., Du, Z., Jock, S., and Geider, K. 2006. Epiphytic Erwinias to control fire blight. Acta Hortic. 704:289-292.

Jakovljevic, V., Jock, S., Du, Z., and Geider, K. 2008. Hypersensitive response and acyl-homoserine lactone production of the fire blight antagonists Erwinia tasmaniensis and Erwinia billingiae. Microb. Biotechnol. 1:416-424.

Johnson, K. B., and Stockwell, V. O. 1998. Management of fire blight: A case study in microbial ecology. Annu. Rev. Phytopathol. 36:227-248.

Katoh, K., and Standley, D. M. 2013. MAFFT multiple sequence alignment software version 7: Improvements in performance and usability. Mol. Biol. Evol. 30:772-780.

Kawasaki, E. S. 1990. Sample preparation from blood, cells and other fluids. Page 146-152 in: PCR Protocols: A Guide to Methods and Applications. M. A. Innis, D. H. Gelfand, J. J. Sninsky, and T. J. White, eds. Academic Press, New York, NY, U.S.A.

King, E. O., Ward, M. K., and Raney, D. E. 1954. Two simple media for the demonstration of pyocyanin and fluorescin. J. Lab. Clin. Med. 44:301-307.

Kostick, S. A., Norelli, J. L., and Evans, K. M. 2019. Novel metrics to classify fire blight resistance of 94 apple cultivars. Plant Pathol. 68:985-996.

Kunz, S. 2004. Development of "Blossom-Protect"-A yeast preparation for the reduction of blossom infections by fire blight. In: 11 th Int. Conf. Cultiv. Tech. Phytopathol. Probl. Org. Fruit-Grow. Vitic.

Martin, M. 2011. Cutadapt removes adapter sequences from high-throughput sequencing reads. EMBnet. J. 17:10-12.

Mayerhofer, J., Eckard, S., Hartmann, M., Grabenweger, G., Widmer, F., Leuchtmann, A., and Enkerli, J. 2017. Assessing effects of the entomopathogenic fungus Metarhizium brunneum on soil microbial communities in Agriotes spp. biological pest control. FEMS Microbiol. Ecol. 93:fix117.

Mergaert, J., Hauben, L., Cnockaert, M. C., and Swings, J. 1999. Reclassification of non- pigmented Erwinia herbicola strains from trees as Erwinia billingiae sp. nov. Int. J. Syst. Bacteriol. 49:377-383.

Mikiciński, A., Puławska, J., Molzhigitova, A., and Sobiczewski, P. 2020. Bacterial species recognized for the first time for its biocontrol activity against fire blight (Erwinia amylovora). Eur. J. Plant Pathol. 156:257-272.

Mikiciński, A., Sobiczewski, P., Puławska, J., and Malusa, E. 2016. Antagonistic potential of Pseudomonas graminis 49M against Erwinia amylovora, the causal agent of fire blight. Arch. Microbiol. 198:531-539.

Myung, I. S., Lee, J. Y., Yun, M. J., Lee, Y. H., Lee, Y. K., Park, D. H., and Oh, C. S. 2016. Fire blight of apple, caused by Erwinia amylovora, a new disease in Korea. Plant Dis. 100:1774.

Nilsson, R. H., Larsson, K.-H., Taylor, A. F. S., Bengtsson-Palme, J., Jeppesen, T. S., Schigel, D., Kennedy, P., Picard, K., Glöckner, F. O., Tedersoo, L., Saar, I., Kõljalg, U., and Abarenkov, K. 2019. The UNITE database for molecular identification of fungi: Handling dark taxa and parallel taxonomic classifications. Nucleic Acids Res. 47:D259-D264.

Norelli, J. L., Jones, A. L., and Aldwinckle, H. S. 2003. Fire blight management in the twenty-first century: Using new technologies that enhance host resistance in apple. Plant Dis. 87:756-765.

Oksanen, J., Blanchet, F. G., Friendly, M., Kindt, R., Legendre, P., McGlinn, D., and Wagner, H. 2018. vegan: Community ecology package. Version 2.4-6. https://cran.r-project.org/web/packages/vegan/index.html

Park, D. H., Yu, J. G., Oh, E. J., Han, K. S., Yea, M. C., Lee, S. J., Myung, I. S., Shim, H. S., and Oh, C. S. 2016. First report of fire blight disease on Asian pear caused by Erwinia amylovora in Korea. Plant Dis. 100:1946.

Parte, A. C. 2018. LPSN_List of prokaryotic names with standing in nomenclature (bacterio.net), 20 years on. Intl. J. Syst. Evol. Microbiol. 68:1825-1829.

Paternoster, T., Défago, G., Duffy, B., Gessler, C., and Pertot, I. 2010. Selection of a Biocontrol agent based on a potential mechanism of action: Degradation of nicotinic acid, a growth factor essential for Erwinia amylovora. Int. Microbiol. 13:195-206.

Perlman, S. J., Hunter, M. S., and Zchori-Fein, E. 2006. The emerging diversity of Rickettsia. Proc. Biol. Sci. 273:2097-2106.

Piano, S., Neyrotti, V., Migheli, Q., and Lodovica Gullino, M. 1997. Biocontrol capability of Metschnikowia pulcherrima against Botrytis postharvest rot of apple. Postharvest Biol. Technol. 11:131-140.

Poudel, R., Jumpponen, A., Schlatter, D. C., Paulitz, T. C., McSpadden Gardener, B. B., Kinkel, L. L., and Garrett, K. A. 2016. Microbiome networks: A systems framework for Identifying candidate microbial assemblages for disease management. Phytopathology 106:1083-1096.

Pujol, M., Badosa, E., Cabrefiga, J., and Montesinos, E. 2005. Development of a strain-specific quantitative method for monitoring Pseudomonas fluorescens EPS62e, a novel biocontrol agent of fire blight. FEMS Microbiol. Lett. 249: $343-352$. 
Pusey, P. L., and Curry, E. A. 2004. Temperature and pomaceous flower age related to colonization by Erwinia amylovora and antagonists. Phytopathology 94:901-911.

Pusey, P. L., Stockwell, V. O., Reardon, C. L., Smits, T. H. M., and Duffy, B. 2011. Antibiosis activity of Pantoea agglomerans biocontrol strain E325 against Erwinia amylovora on apple flower stigmas. Phytopathology 101: 1234-1241.

Quast, C., Pruesse, E., Yilmaz, P., Gerken, J., Schweer, T., Yarza, P., Peplies, J., and Glöckner, F. O. 2013. The SILVA ribosomal RNA gene database project: Improved data processing and web-based tools. Nucleic Acids Res. 41: D590-D596.

R Core Team. 2016. R: A Language and Environment for Statistical Computing. R Foundation for Statistical Computing, Vienna, Austria. https://www.Rproject.org/

Reysenbach, A., and Pace, N. 1995. Reliable amplification of hyperthermophilic archaeal 16S rRNA genes by the polymerase chain reaction. Pages 101-107 in: Archaea: A Laboratory Manual. F. Robb, ed. Cold Spring Harbor Laboratory Press, New York, NY, U.S.A.

Rhim, S.-L., Völksch, B., Gardan, L., Paulin, J.-P., Langlotz, C., Kim, B.-S., and Geider, K. 1999. Erwinia pyrifoliae, an Erwinia species different from Erwinia amylovora, causes a necrotic disease of Asian pear trees. Plant Pathol. 48:514-520.

Roselló, G., Bonaterra, A., Francés, J., Montesinos, L., Badosa, E., and Montesinos, E. 2013. Biological control of fire blight of apple and pear with antagonistic Lactobacillus plantarum. Eur. J. Plant Pathol. 137:621-633.

Schloss, P. D., Westcott, S. L., Ryabin, T., Hall, J. R., Hartmann, M., Hollister, E. B., Lesniewski, R. A., Oakley, B. B., Parks, D. H., Robinson, C. J., Sahl, J. W., Stres, B., Thallinger, G. G., Horn, D. J. V., and Weber, C. F. 2009. Introducing mothur: Open-source, platform-independent, communitysupported software for describing and comparing microbial communities. Appl. Environ. Microbiol. 75:7537-7541.

Seibold, A., Fried, A., Kunz, S., Moltmann, E., Lange, E., and Jelkmann, W. 2004. Yeasts as antagonists against fireblight. Bull. OEPP/EPPO Bull. 34: 389-390.

Seibold, A., Viehrig, M., and Jelkmann, W. 2006. Yeast as antagonist against Erwinia amylovora. Acta Hortic. 704:367-370.

Shade, A., McManus, P. S., and Handelsman, J. 2013. Unexpected diversity during Community succession in the apple flower microbiome. MBio 4: e00602-12.
Shrestha, R., Koo, J. H., Park, D. H., Hwang, I. G., Hur, J. H., and Lim, C. K. 2003. Erwinia pyrifoliae, a causal endemic pathogen of shoot blight of Asian pear tree in Korea. Plant Pathol. J. 19:294-300.

Smits, T. H. M., Rezzonico, F., Blom, J., Goesmann, A., Abelli, A., Morelli, R. K., Vanneste, J. L., and Duffy, D. 2015. Draft genome sequence of the commercial biocontrol strain Pantoea agglomerans P10c. Genome Announce. 3:e01448-15.

Steven, B., Huntley, R. B., and Zeng, Q. 2018. The influence of flower anatomy and apple cultivar on the apple flower phytobiome. Phytobiomes J. 2:171-179.

Stockwell, V. O., Johnson, K. B., and Loper, J. E. 1998. Establishment of bacterial antagonists of Erwinia amylovora on pear and apple blossoms as influenced by inoculum preparation. Phytopathology 88:506-513.

Sundin, G. W., Werner, N. A., Yoder, K. S., and Aldwinckle, H. S. 2009. Field evaluation of biological control of fire blight in the eastern United States. Plant Dis. 93:386-394.

Tedersoo, L., Bahram, M., Põlme, S., Kõljalg, U., Yorou, N. S., Wijesundera, R., Ruiz, L. V., Vasco-Palacios, A. M., Thu, P. Q., Suija, A., Smith, M. E., Sharp, C., Saluveer, E., Saitta, A., Rosas, M., Riit, T., Ratkowsky, D., Pritsch, K., Põldmaa, K., Piepenbring, M., Phosri, C., Peterson, M., Parts, K., Pärtel, K., Otsing, E., Nouhra, E., Njouonkou, A. L., Nilsson, R. H., Morgado, L. N., Mayor, J., May, T. W., Majuakim, L., Lodge, D. J., Lee, S. S., Larsson, K.-H., Kohout, P., Hosaka, K., Hiiesalu, I., Henkel, T. W., Harend, H., Guo, L.-D., Greslebin, A., Grelet, G., Geml, J., Gates, G., Dunstan, W., Dunk, C., Drenkhan, R., Dearnaley, J., De Kesel, A., Dang, T., Chen, X., Buegger, F., Brearley, F. Q., Bonito, G., Anslan, S., Abell, S., and Abarenkov, K. 2014. Global diversity and geography of soil fungi. Science 346:1256688.

van der Zwet, T., and Bonn, W. G. 1999. Recent spread and current worldwide distribution of fireblight. Acta Hortic. 489:167-168.

Vanneste, J. L., Cornish, D. A., Yu, J., and Spinelli, F. 2006. Establishment and survival on apple and pear leaves of four biological control agents including Pantoea agglomerans and Pseudomonas fluorescens A506. Acta Hortic. 704: 307-312.

Weisburg, W. G., Barns, S. M., Pelletier, D. A., and Lane, D. J. 1991. 16S ribosomal DNA amplification for phylogenetic study. J. Bacteriol. 173:697-703.

Wensing, A., Gernold, M., and Geider, K. 2011. Detection of Erwinia species from the apple and pear flora by mass spectroscopy of whole cells and with novel PCR primers. J. Appl. Microbiol. 112:147-158.

Wilson, M., and Lindow, S. E. 1993. Interaction between the biological control agent Pseudomonas fluorescens A506 and Erwinia amylovora in pear blossoms. Acta Hortic. 338:329-330. 